\title{
Investigation of Occupational Burnout Levels of Physical Education and Sports Teachers in Terms of Various Factors: The Case of Bayburt and Gümüşhane Provinces
}

\author{
İsmail Karataş (Corresponding author) \\ Faculty of Sports Sciences, Bayburt University, Bayburt, Turkey \\ E-mail: ismailkrts34@gmail.com
}

Taner Bozkuş

Faculty of Sports Sciences, Bartın University, Bartın, Turkey

E-mail: tanerbozkus@yahoo.com

Received: November 28, 2021

doi:10.5296/jei.v8i1.19387
Accepted: January 9, 2022 Published: February 8, 2022

URL: https://doi.org/10.5296/jei.v8i1.19387

\begin{abstract}
This research examines the occupational burnout levels of physical education and sports teachers in terms of various factors. In this context, the general survey model, which is consistent with the main purpose of the study, is used in this quantitative study. The survey pool of the research consists of a total of 67 physical education and sports teachers, 5 females and 62 males, working in Bayburt and Gümüşhane provinces. Convenience sampling method, one of the non-probability sampling approaches, is used in the selection of the research group. Data collection tool is a questionnaire form which consists of two parts. In the first part of the questionnaire, there is the "Personal Information Form", and in the second part, there is the "Maslach Burnout Inventory-Educator Form". Difference and correlation tests are used in statistical evaluations. Accordingly, significant differences are present in the factors of gender, perceived welfare level and exercise status. However, within the scope of marital status, status of being a manager at the current school, current level of duty, location of the current school, perceived personal income level, perceived family income level (including personal income), active sports status and the type of the active sport, there is no significant difference in the sub-dimensions of the scale. However, the research concludes that there are positive
\end{abstract}


and significant relationships between the participants' total years of service in the teaching profession and the mean scores of the sub-dimensions of emotional exhaustion and depersonalization. On the other hand, there is no significant relationship between the factors of age and years of service in the teaching profession for the school where they are currently employed, and the sub-dimensions of the scale. As a result, occupational burnout levels of physical education and sports teachers within the scope of various factors are described as they exist.

Keywords: Teacher, Physical education and sports teacher, Occupational burnout

\section{Introduction}

The prevalence of burnout, and especially the burnout of educators, is not a recent development (Aboagye et al., 2018). In this context, teachers' mental health has a widespread effect not only on the effectiveness of teaching (İpek et al., 2018), but also on students' personal and emotional development and academic success (Blazer, 2010; Ju et al., 2015; Zhang \& Sap, 2008). Since teaching is a profession with high mental risks (Kyriacou, 2001), many studies have focused on teachers' well-being and mental health (Parker et al., 2012; Van Droogenbroeck \& Spruyt, 2015). Burnout is a psychological response to chronic and work-related stress characterized by emotional exhaustion, depersonalization, and a low sense of personal accomplishment (Maslach, Schaufeli, \& Leiter, 2001). Due to burnout, teachers suffer greatly from psychological and physiological conditions such as anxiety, depression, and cardiovascular disease, and they are more likely to quit their profession (Dimsdale, 2008; Gunnar \& Quevedo, 2007; Hoglund, Klingle, \& Hosan, 2015; Maslach, Schaufeli, \& Lieter, 2001). In addition, various studies, including studies on teachers, have shown that burnout is an effective factor on health and productivity (Ahola et al., 2008; Dewa et al., 2014; Honkonen et al., 2006; Mohren et al., 2003; Consiglio, 2014; Pedersen et al., 2016; Potter, 2006; Rios-Risquez and Garcia-Izquierdo, 2016; Brunsting, Sreckovic, and Lane, 2014; Hoglund et al., 2015; Rudow, 1999).

Burnout is a negative physical and psychological reaction to long-term and interpersonal stress at work, which manifests itself as a series of disorders as well as changing work-related attitudes and behaviors (Maslach, Schaufeli, \& Leiter, 2001; Toppinen-Tanner, Kalimo, \& Mutanen, 2002; Shepherd, Tashchian and Ridnour, 2011). In this respect, the concept of burnout has emotional, mental and physical consequences and is expressed by the exhaustion of the individual's energy (Schaufeli, Leiter, \& Maslach, 2009). The negative consequences of burnout, which occurs as a result of the internal evaluations of the employees within the scope of their relations with the individuals they serve, are reflected on the relevant individuals and employees (İnce \& Şahin, 2015). It is claimed that burnout is the situation when emotional states such as being irritable or feeling depressed and tired, which are rarely felt in matters related to their work, cease to be a rare phenomenon and become permanent (Hayes \& Weathington, 2007). In this context, teachers are increasingly stressed as high levels of psychological distress and burnout threaten their ability to be successful and satisfied in their profession (Greenberg, Brown, \& Abenavoli, 2016; Ouellette et al., 2018). Accordingly, burnout has been associated with decreased organizational commitment (for 
example, increased absenteeism and turnover), low job satisfaction, and poor job performance (Maslach \& Jackson, 1981; Fogarty et al., 2000; Law, 2010).

The concept of work-related stress can be defined as a negative reaction to excessive pressure put on employees in the work context (Bartholomew et al., 2014). It is claimed that almost one of the public school teachers felt high levels of stress during the school year (Gallup, 2014; Markow, Macia, \& Lee, 2013). In addition, physical education and sports teachers are engaged in educational activities at both primary and secondary education levels. Physical education and sports teaching is a special teacher category (Trudeau, Laurencelle, \& Lajoie, 2015), and it is claimed that these teachers have a heavy workload (Sandmark et al., 1999). In this context, burnout among teachers, including physical education and sports teachers (Smith \& Leng, 2003), has a high prevalence rate (Kyriacou, 2001). Accordingly, it is believed that it is important to survey the burnout levels of physical education and sports teachers and to examine these levels within the scope of various factors, and the results obtained will contribute to the relevant literature. In this context, the aim of the research is to examine the occupational burnout levels of physical education and sports teachers in terms of various factors. In this direction, the general survey model, which is consistent with the main purpose of this quantitative research, is used. In this context, a compatible questionnaire form was prepared for the purpose and the raw data obtained as a result of the application of this form to the study group were converted into results by using various statistical analysis techniques. Therefore, the results obtained based on the findings were discussed within the framework of the relevant literature and the research was detailed. And within the scope of various factors, the occupational burnout levels of physical education and sports teachers have been tried to be explained as they exist.

\section{Material and Method}

In this part of the study, the research model, survey pool, data collection tools and data analysis are explained under separate headings.

\subsection{Research Model}

Survey studies generally aim to describe the current situation, by presenting it, related to the subject of the research (Büyüköztürk et al., 2020). In addition, survey researchers are generally interested in how characteristics and opinions are distributed within the scope of the participants in the sample, rather than why they originate (Fraenkel \& Wallen, 2006). In this context, the general survey model, which is consistent with the main purpose of this quantitative research, is used.

\subsection{Survey Pool}

The survey pool of the research consists of a total of 67 physical education and sports teachers, 5 women and 62 men, chosen among 110 physical education and sports teachers working in public schools affiliated to the Ministry of National Education in the provinces of Bayburt (approximately 40 teachers) and Gümüşhane (approximately 70 teachers) in the Spring Term of the 2020-2021 Academic Year. Convenience sampling method, which is one of the non-probability sampling approaches, is used in the creation of the survey pool. 


\subsection{Data Collection Tools}

The questionnaire form, which was prepared in accordance with the aims of the research, had been applied to the participants in the study group on the internet between 27.06.2021 and 12.09.2021 on a voluntary basis. During the use of the data collection tools, necessary explanations were given to the participants and it was ensured that they answered the questionnaire correctly. This form consists of two parts. In the first part of the questionnaire, there is the "Personal Information Form", and in the second part, there is the "Maslach Burnout Inventory-Educator Form".

\subsubsection{Personal Information Form}

In the Personal Information Form, there are statements for obtaining the information regarding the participants' gender, age, marital status, the status of being a manager at the current school, the current level of duty, and the location of the current school, total years of service as a teacher, years of service as a teacher at the current school, perceived welfare level, perceived personal income level, perceived family income level (including personal income), actively doing sports, type of active sports and doing exercise status.

\subsubsection{Maslach Burnout Inventory-Educator Form}

The "Occupational Burnout Inventory" developed by Maslach and Jackson (1981) to determine the level of occupational burnout and the "Maslach Burnout Inventory-Educator Form", which was edited with minor changes for educators by Maslach, Jackson and Schwab, was adapted into Turkish by İnce and Şahin (2015). Data on the adaptation process of the scale were obtained from 760 classroom teachers working in the central and provincial districts of Ankara. The scale consists of 22 items and is in seven-point Likert type. In addition, the scale consists of three sub-dimensions: emotional exhaustion, depersonalization and personal accomplishment. The construct validity of the scale was determined by confirmatory factor analysis. In addition, the internal consistency coefficients (Cronbach's alpha) are calculated as 0.88 for the emotional exhaustion sub-dimension, 0.78 for the depersonalization sub-dimension, and 0.74 for the personal accomplishment sub-dimension. As a result, it was concluded that the Maslach Burnout Inventory-Educator Form is a valid and reliable measurement tool (İnce \& Şahin, 2015).

\subsection{Analysis of the Data}

IBM SPSS 23.0 version was used in the analysis of the data. As a result of the normality test regarding the distribution of the data, it was accepted that the data did not exhibit a normal distribution. First of all, descriptive statistics of the raw data, obtained and transferred to the program, in the scale form were calculated by considering the data type. Then, in the statistical evaluation of the data obtained, Mann-Whitney U and Kruskal Wallis tests were used for difference tests, and Spearman Rank Correlation Analysis was used for correlation tests. In addition, the significance level was determined as 0.05 in statistical evaluations.

\section{Results}

In this part of the study, the findings obtained as a result of the analysis of the relevant data 
were presented and interpreted in the form of tables.

Table 1. Frequency and percentages of the factors

\begin{tabular}{|c|c|c|c|}
\hline Factor & Group & f & $\%$ \\
\hline \multirow{2}{*}{ Gender } & Female & 5 & 7.5 \\
\hline & Male & 62 & 92.5 \\
\hline \multirow{2}{*}{ Marital Status } & Married & 51 & 76.1 \\
\hline & Single & 16 & 23.9 \\
\hline \multirow{2}{*}{ Status of Being a Manager at the Current School } & Yes & 11 & 16.4 \\
\hline & No & 56 & 83.6 \\
\hline \multirow{2}{*}{ Current Duty Level } & Primary & 22 & 32.8 \\
\hline & Secondary & 45 & 67.2 \\
\hline \multirow{3}{*}{ Location of the Current School } & Village + Town & 13 & 19.4 \\
\hline & County Seat & 18 & 26.9 \\
\hline & City Center & 36 & 53.7 \\
\hline \multirow{3}{*}{ Perceived Welfare Level } & Lower Level & 15 & 22.4 \\
\hline & Intermediate Level & 51 & 76.1 \\
\hline & Upper Level & 1 & 1.5 \\
\hline \multirow{3}{*}{ Perceived Personal Income Level } & Low & 16 & 23.9 \\
\hline & Intermediate & 50 & 74.6 \\
\hline & High & 1 & 1.5 \\
\hline \multirow{3}{*}{ Perceived Family Income Level (Including Personal Income) } & Low & 9 & 13.4 \\
\hline & Intermediate & 57 & 85.1 \\
\hline & High & 1 & 1.5 \\
\hline \multirow{2}{*}{ Actively Doing Sports Status } & Yes & 38 & 56.7 \\
\hline & No & 29 & 43.3 \\
\hline \multirow{2}{*}{ Type of Sport If Actively Doing Sports } & Individual Sports & 30 & 44.8 \\
\hline & Team Sport & 8 & 11.9 \\
\hline \multirow{2}{*}{ Exercise Status } & Yes & 51 & 76.1 \\
\hline & No & 16 & 23.9 \\
\hline \multicolumn{2}{|l|}{ Total } & $\mathrm{n}=67$ & 100.0 \\
\hline
\end{tabular}




\section{Ml Macrothink}

When Table 1 is examined, it is seen that the number of men related to the participants is considerably higher than the number of women; the number of married people is higher than the number of singles; and the number of those who do not have a managerial position is considerably higher than the number of those who do. The number of teachers working in secondary education is higher than the number of teachers working in primary education. In terms of place of duty, the group with the highest number of participants is the city centre. It is seen that the group with the highest number of participants in terms of the level of perceived welfare has the middle level, while the higher level group has the lowest number of participants. When the participants' perceived personal income level and perceived family income level (including personal income) are evaluated, it is seen that the middle income group has the highest number of participants and the high income group has the lowest number of participants. It has been determined that the participants who do exercise and participants who do sports have a higher number than those who do not. In addition, the number of those who actively do individual sports is higher than the number of those who do team sports.

Table 2. Descriptive statistics of the factors of age, total number of years in service in the profession, and number of years in service at the current school

\begin{tabular}{|l|l|l|l|l|l|l|}
\hline Factor & $\mathbf{n}$ & Average & Median & Std. Divergence & Minimum & Maximum \\
\hline Age & 67 & 36.657 & 36.000 & 6.8789 & 26.0 & 53.0 \\
\hline $\begin{array}{l}\text { Total Number of Years in Service } \\
\text { as a Teacher }\end{array}$ & 67 & 11.284 & 11.000 & 6.7662 & 2.0 & 26.0 \\
\hline $\begin{array}{l}\text { Number of Years in Service as a } \\
\text { Teacher at the Current School }\end{array}$ & 65 & 5.846 & 4.000 & 4.7672 & 1.0 & 23.0 \\
\hline
\end{tabular}

According to Table 2, the average of the age factor of the participants is 36.657 and the standard deviation is 6.8789 ; the average of the total number of years in service as a teacher is 11.284 and the standard deviation is 6.7662 ; the average of the factor of the number of years in service as a teacher at the current school is 5.846 and the standard deviation is 4.7672 .

Table 3. Results of reliability analysis of the scale sub-dimensions

\begin{tabular}{|l|l|l|}
\hline Sub-Dimensions & Cronbach's Alpha & Item Number \\
\hline Emotional Exhaustion & .917 & 9 \\
\hline Depersonalization & .899 & 5 \\
\hline Personal Accomplishment & .878 & 8 \\
\hline
\end{tabular}




\section{Macrothink}

According to Table 3, within the scope of internal consistency coefficients (cronbach's alpha) calculated within the scope of the research, Emotional exhaustion $(\alpha=0.917)$, depersonalization $(\alpha=0.899)$ and personal accomplishment $(\alpha=0.878)$ sub-dimensions were found to be quite reliable in the context of the Maslach Burnout Inventory-Educator Form.

Table 4. Scores of scale sub-dimensions and corresponding levels of these scores

\begin{tabular}{|l|l|l|l|}
\hline Factors & Average & Std. Divergence & Levels \\
\hline Emotional Exhaustion & 17.4328 & 12.94420 & Intermediate Level \\
\hline Depersonalization & 3.9552 & 5.03753 & Low-Level \\
\hline Personal Accomplishment* & 11.2836 & 8.22193 & High Level \\
\hline
\end{tabular}

Note. * In order to avoid difficulties in interpreting this table, analyzes were carried out in the context of Feeling of Failure or Personal Failure, as opposed to the Personal Accomplishment Sub-Dimension.

In Table 4, when evaluation is made according to the levels created by Maslach, Jackson, and Leiter (2010), It is seen that the emotional exhaustion of the participants is very close to the low level and at a moderate level; their depersonalization is at a low level and their sense of personal accomplishment is at a high level.

Table 5. Descriptive statistics of the scale sub-dimensions

\begin{tabular}{|l|l|l|l|l|l|l|}
\hline Sub-Dimensions & $\mathbf{n}$ & Average & Median & Std. Divergence & Minimum & Maximum \\
\hline Emotional Exhaustion & 67 & 1.9370 & 1.5556 & 1.43824 & .00 & 5.67 \\
\hline Depersonalization & 67 & .7910 & .6000 & 1.00751 & .00 & 5.40 \\
\hline Personal Accomplishment & 67 & 4.5896 & 4.8750 & 1.02774 & 1.38 & 6.00 \\
\hline
\end{tabular}

When Table 5 is examined, the mean score of the emotional exhaustion sub-dimension is 1.9370 and the standard deviation is 1.43824; The mean score of the depersonalization sub-dimension is 0.7910 and the standard deviation is 1.00751 , and the mean score of the personal accomplishment sub-dimension is 4.5896 and the standard deviation is 1.02774 . 
Table 6. Results of Spearman's rank-order correlation analysis between age, total number of years in service in the profession, and number of years in service at the current school factors and the scale sub-dimensions

\begin{tabular}{|c|c|c|c|c|}
\hline \multicolumn{2}{|l|}{ Factors } & $\begin{array}{l}\text { Emotional } \\
\text { Exhaustion }\end{array}$ & Depersonalization & $\begin{array}{l}\text { Personal } \\
\text { Accomplishment }\end{array}$ \\
\hline \multirow{3}{*}{ Age } & $\mathbf{r}$ & .144 & .210 & .029 \\
\hline & $\mathbf{p}$ & .246 & .088 & .817 \\
\hline & n & 67 & 67 & 67 \\
\hline \multirow{3}{*}{$\begin{array}{l}\text { Total Number of Years in Service } \\
\text { as a Teacher }\end{array}$} & $\mathbf{r}$ & $.309^{*}$ & $.278^{*}$ & .005 \\
\hline & $\mathbf{p}$ & .011 & .023 & .966 \\
\hline & n & 67 & 67 & 67 \\
\hline \multirow{3}{*}{$\begin{array}{l}\text { Number of Years in Service as a } \\
\text { Teacher at the Current School }\end{array}$} & $\mathbf{r}$ & .034 & .030 & .135 \\
\hline & $\mathbf{p}$ & .785 & .811 & .284 \\
\hline & $\mathbf{n}$ & 65 & 65 & 65 \\
\hline
\end{tabular}

Note. ${ }^{*} \mathrm{p}<0.05$.

According to Table 6 , it is seen that there is a statistically significant and moderately positive relationship between the total number of years in service as a teacher and emotional exhaustion $(r=0.309 ; p=0.011<0.05)$. In addition, it was found that there is a low level of statistically significant positive correlation between total years of service in the teaching profession and depersonalization $(r=0.278 ; p=0.023<0.05)$. However, no statistically significant relationship was found between the sub-dimensions of the burnout inventory and the factors of age and number of years in service as a teacher at the current school ( $p>0.05)$.

Table 7. Mann-Whitney U test results according to gender factor

\begin{tabular}{|c|c|c|c|c|c|c|}
\hline Sub-Dimensions & Gender & $\mathbf{n}$ & Mean Rank & Rank Sum & $\mathbf{U}$ & $\mathbf{p}$ \\
\hline \multirow{2}{*}{ Emotional Exhaustion } & Female & 5 & 14.10 & 70.50 & \multirow{2}{*}{$55.500^{*}$} & \multirow{2}{*}{.018} \\
\hline & Male & 62 & 35.60 & 2207.50 & & \\
\hline \multirow{2}{*}{ Depersonalization } & Female & 5 & 12.50 & 62.50 & \multirow{2}{*}{$47.500^{*}$} & \multirow{2}{*}{.009} \\
\hline & Male & 62 & 35.73 & 2215.50 & & \\
\hline \multirow{2}{*}{ Personal Accomplishment } & Female & 5 & 29.60 & 148.00 & \multirow{2}{*}{133.000} & \multirow{2}{*}{.599} \\
\hline & Male & 62 & 34.35 & 2130.00 & & \\
\hline
\end{tabular}

Note. ${ }^{*} \mathrm{p}<0.05$ 


\section{Macrothink $\Delta$ Institute ${ }^{\text {tim }}$}

When Table 7 is examined, it is seen that there is a statistically significant difference between the emotional exhaustion of women and the emotional exhaustion of men $(U=55,500 ; p<$ 0.05). It was found that this significant difference was in favor of men. In addition, a statistically significant difference was found between depersonalization of women and depersonalization of men $(U=47.500 ; p<0.05)$. It was found that this significant difference was in favor of men. However, it is seen that there is no statistically significant difference in terms of personal accomplishment sub-dimension scores in the context of gender factor $(p>$ $0.05)$.

Table 8. Mann-Whitney U test results according to marital status factor

\begin{tabular}{|c|c|c|c|c|c|c|}
\hline Sub-Dimensions & Marital Status & $\mathbf{n}$ & Mean Rank & Rank Sum & $\mathbf{U}$ & $\mathbf{p}$ \\
\hline \multirow{2}{*}{ Emotional Exhaustion } & Married & 51 & 34.60 & 1764.50 & \multirow{2}{*}{377.500} & \multirow{2}{*}{.654} \\
\hline & Single & 16 & 32.09 & 513.50 & & \\
\hline \multirow{2}{*}{ Depersonalization } & Married & 51 & 34.00 & 1734.00 & \multirow{2}{*}{408.000} & \multirow{2}{*}{1.000} \\
\hline & Single & 16 & 34.00 & 544.00 & & \\
\hline \multirow{2}{*}{ Personal Accomplishment } & Married & 51 & 35.88 & 1830.00 & \multirow{2}{*}{312.000} & \multirow{2}{*}{.157} \\
\hline & Single & 16 & 28.00 & 448.00 & & \\
\hline
\end{tabular}

When Table 8 was examined, it was determined that there is no statistically significant difference in terms of the scores of the sub-dimensions of the burnout inventory in the context of the marital status factor $(\mathrm{p}>0.05)$.

Table 9. Mann-Whitney $U$ test results according to the factor of having a managerial position at the current school

\begin{tabular}{|c|c|c|c|c|c|c|}
\hline Sub-Dimensions & $\begin{array}{l}\text { Status of Being a Manager } \\
\text { at the Current School }\end{array}$ & $\mathbf{n}$ & Mean Rank & Rank Sum & $\mathbf{U}$ & $\mathbf{p}$ \\
\hline \multirow{2}{*}{ Emotional Exhaustion } & Yes & 11 & 28.14 & 309.50 & \multirow{2}{*}{243.500} & \multirow{2}{*}{.275} \\
\hline & No & 56 & 35.15 & 1968.50 & & \\
\hline \multirow{2}{*}{ Depersonalization } & Yes & 11 & 35.45 & 390.00 & \multirow{2}{*}{292.000} & \multirow{2}{*}{.783} \\
\hline & No & 56 & 33.71 & 1888.00 & & \\
\hline \multirow{2}{*}{ Personal Accomplishment } & Yes & 11 & 36.45 & 401.00 & \multirow{2}{*}{281.000} & \multirow{2}{*}{.647} \\
\hline & No & 56 & 33.52 & 1877.00 & & \\
\hline
\end{tabular}


When Table 9 is examined, it has been determined that there is no statistically significant difference in terms of the scores of the sub-dimensions of the burnout inventory in the context of the factor of having a managerial position at the current school $(p>0.05)$.

Table 10. Mann-Whitney U test results according to the current duty level factor

\begin{tabular}{|c|c|c|c|c|c|c|}
\hline Sub-Dimensions & Current Duty Level & $\mathbf{n}$ & Mean Rank & Rank Sum & $\mathbf{U}$ & $\mathbf{p}$ \\
\hline \multirow{2}{*}{ Emotional Exhaustion } & Primary & 22 & 31.82 & 700.00 & \multirow{2}{*}{447.000} & \multirow{2}{*}{.521} \\
\hline & Secondary & 45 & 35.07 & 1578.00 & & \\
\hline \multirow{2}{*}{ Depersonalization } & Primary & 22 & 28.39 & 624.50 & \multirow{2}{*}{371.500} & \multirow{2}{*}{.094} \\
\hline & Secondary & 45 & 36.74 & 1653.50 & & \\
\hline \multirow{2}{*}{ Personal Accomplishment } & Primary & 22 & 37.57 & 826.50 & \multirow{2}{*}{416.500} & \multirow{2}{*}{.294} \\
\hline & Secondary & 45 & 32.26 & 1451.50 & & \\
\hline
\end{tabular}

When Table 10 is examined, it has been determined that there is no statistically significant difference in terms of the scores of the burnout inventory sub-dimensions in the context of the current duty level factor $(\mathrm{p}>0.05)$.

Table 11. Kruskal-Wallis test results according to the location of the current school factor

\begin{tabular}{|c|c|c|c|c|c|c|}
\hline Sub-Dimensions & Group & n & Mean Rank & sd & $\chi^{2}$ & $\mathbf{p}$ \\
\hline \multirow{3}{*}{ Emotional Exhaustion } & Village + Town & 13 & 34.12 & \multirow{3}{*}{2} & \multirow{3}{*}{1.645} & \multirow{3}{*}{.439} \\
\hline & County Seat & 18 & 29.17 & & & \\
\hline & City Center & 36 & 36.38 & & & \\
\hline \multirow{3}{*}{ Depersonalization } & Village + Town & 13 & 30.96 & \multirow{3}{*}{2} & \multirow{3}{*}{4.215} & \multirow{3}{*}{.122} \\
\hline & County Seat & 18 & 27.53 & & & \\
\hline & City Center & 36 & 38.33 & & & \\
\hline \multirow{3}{*}{ Personal Accomplishment } & Village + Town & 13 & 42.15 & \multirow{3}{*}{2} & \multirow{3}{*}{4.154} & \multirow{3}{*}{.125} \\
\hline & County Seat & 18 & 36.33 & & & \\
\hline & City Center & 36 & 29.89 & & & \\
\hline
\end{tabular}

When Table 11 is examined, it has been determined that there is no statistically significant difference in terms of the scores of the sub-dimensions of the burnout inventory in the 
context of the location of the current school factor $(p>0.05)$.

Table 12. Mann-Whitney $U$ test results according to the perceived welfare level

\begin{tabular}{|c|c|c|c|c|c|c|}
\hline Sub-Dimensions & Perceived Welfare Level** & $\mathbf{n}$ & Mean Rank & Rank Sum & $\mathbf{U}$ & $\mathbf{p}$ \\
\hline \multirow{2}{*}{ Emotional Exhaustion } & Lower Level & 15 & 43.17 & 647.50 & \multirow{2}{*}{$237.500^{*}$} & \multirow{2}{*}{.026} \\
\hline & Intermediate Level & 51 & 30.66 & 1563.50 & & \\
\hline \multirow{2}{*}{ Depersonalization } & Lower Level & 15 & 32.57 & 488.50 & \multirow{2}{*}{368.500} & \multirow{2}{*}{.828} \\
\hline & Intermediate Level & 51 & 33.77 & 1722.50 & & \\
\hline \multirow{2}{*}{ Personal Accomplishment } & Lower Level & 15 & 29.63 & 444.50 & \multirow{2}{*}{324.500} & \multirow{2}{*}{.374} \\
\hline & Intermediate Level & 51 & 34.64 & 1766.50 & & \\
\hline
\end{tabular}

Note. ${ }^{*} \mathrm{p}<0.05 ; * *$ Since there is only one participant in the Upper-Level Welfare group, it was excluded from the analysis.

When Table 12 is examined, it is seen that there is a statistically significant difference between the emotional exhaustion of the participants with a low perceived welfare level and the emotional exhaustion of those with a moderate perceived welfare level $(U=237,500 ; p<$ 0.05). It was found that this significant difference was in favor of the lower level group. On the other hand, it is seen that there is no statistically significant difference in the scores of depersonalization and personal accomplishment sub-dimensions in the context of the perceived welfare level $(\mathrm{p}>0.05)$.

Table 13. Mann-Whitney $U$ test results according to the perceived personal income level factor

\begin{tabular}{|c|c|c|c|c|c|c|}
\hline Sub-Dimensions & Perceived Personal Income Level* & $\mathbf{n}$ & Mean Rank & Rank Sum & $\mathbf{U}$ & $\mathbf{p}$ \\
\hline \multirow{2}{*}{ Emotional Exhaustion } & Low & 16 & 40.66 & 650.50 & \multirow{2}{*}{285.500} & \multirow{2}{*}{.086} \\
\hline & Intermediate & 50 & 31.21 & 1560.50 & & \\
\hline \multirow{2}{*}{ Depersonalization } & Low & 16 & 33.88 & 542.00 & \multirow{2}{*}{394.000} & \multirow{2}{*}{.927} \\
\hline & Intermediate & 50 & 33.38 & 1669.00 & & \\
\hline \multirow{2}{*}{ Personal Accomplishment } & Low & 16 & 28.94 & 463.00 & \multirow{2}{*}{327.000} & \multirow{2}{*}{.274} \\
\hline & Intermediate & 50 & 34.96 & 1748.00 & & \\
\hline
\end{tabular}

Note. * Since there is only one participant in the High Income Level group, it was excluded from the analyses. 
When Table 13 is examined, it has been determined that there is no statistically significant difference in terms of the scores of the burnout inventory sub-dimensions in the context of the perceived personal income level $(p>0.05)$.

Table 14. Mann-Whitney $U$ test results according to the perceived family income level (including personal income) factor

\begin{tabular}{|c|c|c|c|c|c|c|}
\hline Sub-Dimensions & Perceived Family Income Level* & $\mathbf{n}$ & Mean Rank & Rank Sum & $\mathbf{U}$ & $\mathbf{p}$ \\
\hline \multirow{2}{*}{ Emotional Exhaustion } & Low & 9 & 37.17 & 334.50 & \multirow{2}{*}{223.500} & \multirow{2}{*}{.537} \\
\hline & Intermediate & 57 & 32.92 & 1876.50 & & \\
\hline \multirow{2}{*}{ Depersonalization } & Low & 9 & 31.89 & 287.00 & \multirow{2}{*}{242.000} & \multirow{2}{*}{.783} \\
\hline & Intermediate & 57 & 33.75 & 1924.00 & & \\
\hline \multirow{2}{*}{ Personal Accomplishment } & Low & 9 & 22.89 & 206.00 & \multirow{2}{*}{161.000} & \multirow{2}{*}{.074} \\
\hline & Intermediate & 57 & 35.18 & 2005.00 & & \\
\hline
\end{tabular}

Note. * Since there is only one participant in the High Income Level group, it was excluded from the analyses.

When Table 14 is examined, it has been determined that there is no statistically significant difference in the scores of the burnout inventory sub-dimensions in the context of the perceived family income level (including personal income) $(p>0.05)$.

Table 15. Mann-Whitney U test results according to the of actively doing sports status factor

\begin{tabular}{|c|c|c|c|c|c|c|}
\hline Sub-Dimensions & Actively Doing Sports Status & $\mathbf{n}$ & Mean Rank & Rank Sum & $\mathbf{U}$ & $\mathbf{p}$ \\
\hline \multirow{2}{*}{ Emotional Exhaustion } & Yes & 38 & 33.05 & 1256.00 & \multirow{2}{*}{515.000} & \multirow{2}{*}{.648} \\
\hline & No & 29 & 35.24 & 1022.00 & & \\
\hline \multirow{2}{*}{ Depersonalization } & Yes & 38 & 34.07 & 1294.50 & \multirow{2}{*}{548.500} & \multirow{2}{*}{.974} \\
\hline & No & 29 & 33.91 & 983.50 & & \\
\hline \multirow{2}{*}{ Personal Accomplishment } & Yes & 38 & 35.70 & 1356.50 & \multirow{2}{*}{486.500} & \multirow{2}{*}{.413} \\
\hline & No & 29 & 31.78 & 921.50 & & \\
\hline
\end{tabular}

When Table 15 is examined, it has been determined that there is no statistically significant difference in terms of the scores of the burnout inventory sub-dimensions in the context of the actively doing sports factor $(\mathrm{p}>0.05)$. 
Table 16. Mann-Whitney $U$ test results according to the active sport type factor

\begin{tabular}{|l|l|l|l|l|l|l|}
\hline Sub-Dimensions & Active Sport Type & $\mathbf{n}$ & Mean Rank & Rank Sum & U & p \\
\hline \multirow{3}{*}{ Emotional Exhaustion } & Individual Sports & 30 & 20.47 & 614.00 & \multirow{2}{*}{91.000} & \multirow{2}{*}{.298} \\
\cline { 2 - 7 } & Team Sport & 8 & 15.88 & 127.00 & & \\
\hline \multirow{3}{*}{ Depersonalization } & Individual Sports & 30 & 19.85 & 595.50 & \multirow{2}{*}{109.500} & .701 \\
\cline { 2 - 8 } & Team Sport & 8 & 18.19 & 145.50 & & \\
\hline \multirow{2}{*}{ Personal Accomplishment } & Individual Sports & 30 & 18.82 & 564.50 & \multirow{2}{*}{99.500} & .461 \\
\cline { 2 - 7 } & Team Sport & 8 & 22.06 & 176.50 & & \\
\hline
\end{tabular}

When Table 16 is examined, it has been determined that there is no statistically significant difference in terms of the scores of the burnout inventory sub-dimensions in the context of the active sport type factor $(\mathrm{p}>0.05)$.

Table 17. Mann-Whitney U test results according to the exercise status factor

\begin{tabular}{|l|l|l|l|l|l|l|}
\hline Sub-Dimensions & Exercise Status & $\mathbf{n}$ & Mean Rank & Rank Sum & U & p \\
\hline \multirow{3}{*}{ Emotional Exhaustion } & Yes & 51 & 30.98 & 1580.00 & \multirow{2}{*}{$254.000^{*}$} & \multirow{2}{*}{.023} \\
\cline { 2 - 8 } & No & 16 & 43.63 & 698.00 & & \\
\hline \multirow{2}{*}{ Depersonalization } & Yes & 51 & 32.56 & 1660.50 & \multirow{2}{*}{334.500} & .272 \\
\cline { 2 - 8 } & No & 16 & 38.59 & 617.50 & & \\
\hline \multirow{2}{*}{ Personal Accomplishment } & Yes & 51 & 35.89 & 1830.50 & \multirow{2}{*}{311.500} & .155 \\
\cline { 2 - 8 } & No & 16 & 27.97 & 447.50 & & \\
\hline
\end{tabular}

Note. ${ }^{*} \mathrm{p}<0.05$.

When Table 17 is examined, it is seen that there is a statistically significant difference between the emotional exhaustion of the participants who exercise and the emotional exhaustion of the participants who do not exercise $(U=254,000 ; p<0.05)$. It has been determined that this significant difference is in favor of physical education and sports teachers who do not exercise. On the other hand, it is seen that there is no statistically significant difference in terms of depersonalization and personal accomplishment sub-dimensions scores in the context of the exercise status factor $(p>0.05)$.

\section{Discussion}

This research was carried out in order to examine the occupational burnout levels of physical 
education and sports teachers in terms of various factors within the framework of Bayburt and Gümüşhane provinces. In this context, a compatible questionnaire was prepared for research purposes and the raw data obtained as a result of the application of this questionnaire to the study group were converted into findings by using various statistical analysis techniques. In this setting, the results obtained based on the findings were discussed within the framework of the relevant literature and the research was detailed. In this framework, it has been concluded that the emotional exhaustion of the participants is very close to the low level and at a moderate level; their depersonalization is at a low level, and their sense of personal accomplishment is at a high level.

Considering the gender factor, it was found that men's emotional exhaustion and depersonalization levels are higher than women's. Regarding gender, some studies found no difference in the prevalence of burnout between the genders (Ahola et al., 2005; Hastings \& Bham, 2003). In addition, it has been suggested that women experience higher levels of emotional exhaustion, while men experience higher levels of depersonalization (Lackritz, 2004; Schwarzer \& Hallum, 2008). On the other hand, the study of Ahola et al (2005) concluded that men who report severe burnout are three times more likely to experience major depression than women. In this context, considering the branch differences in the context of the teaching profession, it is thought that the results obtained within the scope of the gender factor for this research are likely.

Considering the perceived wealth level factor, it was determined that the emotional exhaustion levels of the participants with a low perceived wealth level are higher than those with a moderate perceived wealth level. Since teachers compromise their well-being, burnout can reduce the quality of teachers' performance and negatively affect their interactions with students (Gerber, Whitebook, \& Weinstein, 2007; Yoon, 2008). It is also stated that teachers' professional burnout is an important indicator of teacher's welfare (Oberle et al., 2020). Therefore, it is thought that the results reached within the scope of the perceived welfare level factor for this research are probable.

Considering the exercise status factor, it was observed that the emotional exhaustion levels of the participants who did not exercise are higher than those of the participants who exercised. In addition, when statistical significance is not taken into account, it is noteworthy that those who do not exercise have higher levels of depersonalization and lower personal accomplishment levels. Physical activity exercises reduce the sympathetic nerve activity stimulated in response to stress, and reduce the level of physiological tension and stress (Vancampfort et al., 2013). In addition, physical exercises reduce the levels of stress hormones such as adrenaline and cortisol in the body and trigger the secretion of hormones such as endorphins that make the individual feel good (Harvard Medical School, 2020). It has been suggested that physical exercise is a remedy for many stress-related physical and mental illnesses (Raglin \& Wilson, 2012). In this context, both researchers and practitioners turn to physical exercise as an effective method to cope with stress and its harmful effects (Chen, 2016; Klaperski, 2018). Therefore, it is understood that the results obtained within the scope of the exercise status factor for this study are consistent. 


\section{Ml Macrothink}

Considering the total number of years in service as a teacher factor, it has been determined that there is a moderately significant positive relationship between the total number of years in service as a teacher and emotional exhaustion. In other words, as the total number of years in service in the profession increase, the level of emotional exhaustion also increases. In addition, it was found that there is a low level of positive correlation between the total number of years in service as a teacher and depersonalization. In other words, as the total number of years in service in the profession increase, the level of depersonalization also increases. Teaching is one of the hardest jobs that leads to extreme levels of stress (Cacha, 1981; Pines, 2002). Behavioral problems, conflicts with colleagues, parent-teacher relationship problems and/or students who adopt new teaching methods are representative examples of the stressors inherent in the teaching profession (Skaalvik \& Skaalvik, 2007). As the length of service in the profession increases, the duration of exposure to these stressors also increases. Therefore, it is thought that the results reached within the scope of the total number of years in service as a teacher for this research are probable.

In the research, any significant difference is observed in the scope of the factors of the marital status, the status of being a manager at the current school, the current duty level, the location of the current school, the perceived personal income level, the perceived family income level (including personal income), actively doing sports and the type of sports actively performed. In addition, no significant relationship was found within the scope of the factors of age and number of years in service as a teacher at the current school. In this context, Maslach and Leiter (1997), in an effort to develop a comprehensive theoretical framework, identified six main effects on burnout: (1) workload; (2) lack of control over setting day-to-day priorities and following them; (3) insufficient reward and the accompanying feeling of constantly having to do more for less gain; (4) the feeling that relationships in the community are depersonalized and teamwork is weakened; (5) lack of trust, transparency, and respect; and (6) the fact that choices made by management often conflict with mission and core values. The existence of these basic effects strengthens the possibility of developing burnout symptoms in an individual, and it should be noted that any of these effects may cause the person to show signs of burnout (Hogan \& McKnight, 2007). In this case, it is concluded that many factors may affect burnout.

\section{Conclusion}

Making plans to increase physical education and sports teachers' welfare levels and their participation in physical exercise can cause a decrease in the feeling of burnout. Accordingly, it is thought that the negativities arising from professional burnout can be reduced. In addition, thanks to the research findings, new information that will contribute to the literature has been reached. However, the results of the analysis include a limited number of participant data considering the survey pool. For this reason, similar studies can be conducted with a large data set that covers all age and gender groups. In addition, research results can be diversified by conducting qualitative, mixed and/or experimental studies on a survey pool with similar characteristics. In this context, different results that will contribute to the literature can be reached. 


\section{References}

Aboagye, M. O., Qin, J., Qayyum, A., Antwi, C. O., Jababu, Y., \& Affum-Osei, E. (2018). Teacher burnout in pre-schools: A cross-cultural factorial validity, measurement invariance and latent mean comparison of the Maslach Burnout Inventory, Educators Survey (MBI-ES). Children and Youth Services Review, 94, 186-197. https://doi.org/10.1016/j.childyouth. 2018.09.041

Ahola, K., Honkonen, T., Isometsa, E., Kalimo, R., Nykyri, E., Aromaa, A., \& Lonnqvist, J. (2005). The relationship between job-related burnout and depressive disorders-results from the Finnish Health 2000 Study. Journal of Affective Disorders, 88, 55-62. https://doi.org/ 10.1016/j.jad.2005.06.004

Ahola, K., Kivimaki, M., Honkonen, T., Virtanen, M., Koskinen, S., Vahtera, J., \& Lonnqvist, J. (2008). Occupational burnout and medically certified sickness absence: A population-based study of finnish employees. Journal of Psychosomatic Research, 64(2), 185-193. https://doi.org/10.1016/j.jpsychores.2007.06.022

Bartholomew, K. J., Ntoumanis, N., Cuevas, R., \& Lonsdale, C. (2014). Job pressure and ill-health in physical education teachers: The mediating role of psychological need thwarting. Teaching and Teacher Education, 37, 101-107. https://doi.org/10.1016/j.tate.2013.10.006

Blazer, C. (2010). Teacher Burnout (Information Capsule 1003).

Brunsting, N. C., Sreckovic, M. A., \& Lane, K. L. (2014). Special education teacher burnout: A synthesis of research from 1979 to 2013. Education \& Treatment of Children, 37(4), 681-711. https://doi.org/10.1353/etc.2014.0032

Büyüköztürk, Ş., Çakmak, E. K., Akgün, Ö. E., Karadeniz, Ş., \& Demirel, F. (2020). Ĕgitimde Bilimsel Araştırma Yöntemleri (29th ed.). Ankara: Pegem Akademi.

Cacha, F. B. (1981). Teacher burnout: Causes and solutions. Kappa Delta Pi Record, 18, 26-27. https://doi.org/10.1080/00228958.1981.10518308

Chen, D. D. (2016). Stress Management and Prevention: Applications to Daily Life. Routledge. https://doi.org/10.4324/9781315695594

Consiglio, C. (2014). Interpersonal strain at work: A new burnout facet relevant for the health of hospital staff. Burnout Research, 1(2), 69-75. https://doi.org/10.1016/j.burn.2014.07.002

Dewa, C. S., Jacobs, P., Thanh, N. X., \& Loong, D. (2014). An estimate of the cost of burnout on early retirement and reduction in clinical hours of practicing physicians in Canada. BMC Health Services Research, 14(1), 1-9. https://doi.org/10.1186/1472-6963-14-254

Dimsdale, J. E. (2008). Psychological stress and cardiovascular disease. Journal of the American College of Cardiology, 51, 1237-1246. https://doi.org/10.1016/j.jacc.2007.12.024

Fogarty, T. J., Singh, J. P., Rhoads, G. K., \& Moore, R. K. (2000). Antecedents and consequences of burnout in accounting: beyond the role stress model. Behavioral Research in Accounting, 12, 31-68. 
Fraenkel, J. R., \& Wallen, N. E. (2006). How to Design and Evaluate Research in Education (6th ed.). New York: McGraw-Hill International Edition.

Gallup. (2014). State of America's schools: A path to winning again in education. Retrieved from http://www.gallup.com/services/178709/state-america-schools-report.aspx?ays_n

Gerber, E. B., Whitebook, M., \& Weinstein, R. S. (2007). At the heart of child care: Predictors of teacher sensitivity in center-based child care. Early Childhood Research Quarterly, 22, 327-346. https://doi.org/10.1016/j.ecresq.2006.12.003

Greenberg, M. T., Brown, J. L., \& Abenavoli, R. M. (2016). Teacher Stress and Health Effects on Teachers, Students, and Schools. Edna Bennett Pierce Prevention Research Center, Pennsylvania State University.

Gunnar, M., \& Quevedo, K. (2007). The neurobiology of stress and development. Annual Review of Psychology, 58, 145-173. https://doi.org/10.1146/annurev.psych.58.110405.085605

Harvard Medical School. (2020). Exercise to relax. How does exercise reduce stress? Surprising answers to this question and more. Retrieved from https://www.health.harvard. edu/staying-healthy/exercising-to-relax

Hastings, R. P., \& Bham, M. S. (2003). The relationship between student behaviour patterns and teacher burnout. School Psychology International, 24(1), 115-127. https://doi.org/ $10.1177 / 0143034303024001905$

Hayes, C. T., \& Weathington, B. L. (2007). Optimism, stress, life satisfaction, and job burnout in restaurant managers. The Journal of Psychology, 141(6), 565-579. https://doi.org/ 10.3200/JRLP.141.6.565-580

Hogan, R. L., \& McKnight, M. A. (2007). Exploring burnout among university online instructors: An initial investigation. The Internet and Higher Education, 10(2), 117-124. https://doi.org/10.1016/j.iheduc.2007.03.001

Hoglund, W. L. G., Klingle, K. E., \& Hosan, N. E. (2015). Classroom risks and resources: Teacher burnout, classroom quality and children's adjustment in high needs elementary schools. Journal of School Psychology, 53(5), 337-357. https://doi.org/10.1016/j.jsp.2015. 06.002

Honkonen, T., Ahola, K., Pertovaara, M., Isometsä, E., Kalimo, R., Nykyri, E., Aromaa, A., \& Lönnqvist, J. (2006). The Association Between Burnout and Physical Illness in the General Population-Results from the Finnish Health 2000 Study. Journal of Psychosomatic Research, 61(1), 59-66. https://doi.org/10.1016/j.jpsychores.2005.10.002

İnce, N. B., \& Şahin, A. E. (2015). The adaptation study of Maslach burnout inventory-educators survey to Turkish. Journal of Measurement and Evaluation in Education and Psychology, 6(2), 385-399.

İpek, H., Akçay, A., Bayındır Atay, S., Berber, G., Karalık, T., \& Yılmaz, T. S. (2018). The relationship between occupational stress and teacher self-efficacy: A study with EFL 
instructors. Anadolu Journal of Educational Sciences International, 8(1), 126-150.

Ju, C., Lan, J., Li, Y., Feng, W., \& You, X. (2015). The mediating role of workplace social support on the relationship between trait emotional intelligence and teacher burnout. Teaching and Teacher Education, 51, 58-67. https://doi.org/10.1016/j.tate.2015.06.001

Klaperski, S. (2018) Exercise, Stress and Health: The Stress-Buffering Effect of Exercise. In R. Fuchs \& M. Gerber (Eds.), Handbuch Stressregulation und Sport. Springer Reference Psychologie. Springer, Berlin, Heidelberg. https://doi.org/10.1007/978-3-662-49322-9_8

Kyriacou, C. (2001). Teacher stress: Directions for future research. Educational Review, 53(1), 27-35. https://doi.org/10.1080/00131910120033628

Lackritz, J. R. (2004). Exploring burnout among university faculty: Incidence, performance, and demographic issues. Teaching and Teacher Education, 20(7), 713-729. https://doi.org/ 10.1016/j.tate.2004.07.002

Law, D. W. (2010). A measure of burnout for business students. Journal of Education for Business, 85, 195-202. https://doi.org/10.1080/08832320903218133

Markow, D., Macia, L., \& Lee, H. (2013). The MetLife Survey of the American Teacher: Challenges for School Leadership. Metropolitan Life Insurance Company.

Maslach, C., \& Jackson, S. E. (1981). The measurement of experienced burnout. Journal of Organizational Behavior, 2(2), 99-113. https://doi.org/10.1002/job.4030020205

Maslach, C., \& Leiter, M. P. (1997). The Truth About Burnout: How Organizations Cause Personal Stress and What to Do About It. San Francisco, CA: Jossey-Bass.

Maslach, C., Jackson, S. E., \& Leiter, M. P. (2010). Maslach Burnout Inventory Manual (3rd ed.). Mindgarden.com.

Maslach, C., Schaufeli, W. B., \& Leiter, M. P. (2001). Job burnout. Annual Review of Psychology, 52, 397-422. https://doi.org/10.1146/annurev.psych.52.1.397

Mohren, D. C. L., Swaen, G. M. H., Kant, I., van Amelsvoort, L. G. P. M., Borm, P. J. A., \& Galama, J. M. D. (2003). Common infections and the role of burnout in a Dutch working population. Journal of Psychosomatic Research, 55(3), 201-208. https://doi.org/10.1016/ S0022-3999(02)00517-2

Oberle, E., Gist, A., Cooray, M. S., \& Pinto, J. B. R. (2020). Do students notice stress in teachers? Associations between classroom teacher burnout and students' perceptions of teacher social-emotional competence. Psychology in the Schools, 57(11), 1741-1756. https://doi.org/10.1002/pits.22432

Ouellette, R. R., Frazier, S., Shernoff, E., Capella, E., Mehta, R., Marinez-Lora, A., ... Atkins, M. S. (2018). Teacher job stress and satisfaction in urban schools: Disentangling individual, classroom, and organizational-level influences. Behavior Therapy, 49(4), 494-508. https://doi.org/10.1016/j.beth.2017.11.011 


\section{Ml Macrothink}

Parker, P. D., Martin, A. J., Colmar, S., \& Liem, G. A. (2012). Teachers' workplace well-being: Exploring a process model of goal orientation, coping behavior, engagement, and burnout. Teaching and Teacher Education, 28(4), 503-513. https://doi.org/10.1016/j.tate.2012.01.001

Pedersen, A. F., Sørensen, J. K., Bruun, N. H., Christensen, B., \& Vedsted, P. (2016). Risky alcohol use in Danish physicians: Associated with alexithymia and burnout? Drug and Alcohol Dependence, 160, 119-126. https://doi.org/10.1016/j.drugalcdep.2015.12.038

Pines, A. M. (2002). Teacher burnout: A psychodynamic existential perspective. Teachers and Teaching: Theory and Practice, 8, 121-140. https://doi.org/10.1080/13540600220127331

Potter, C. (2006). To what extent do nurses and physicians working within the emergency department experience burnout: A review of the literature. Australasian Emergency Nursing Journal, 9(2), 57-64. https://doi.org/10.1016/j.aenj.2006.03.006

Raglin, J., \& Wilson, G. (2012). Exercise and Its Effects on Mental Health. In C. Bouchard, S. Blair, \& W. Haskell (Eds.), Physical Activity and Health (pp. 331-342). Leeds: HK. https://doi.org/10.5040/9781492595717.ch-021

Rios-Risquez, M. I., \& Garcia-Izquierdo, M. (2016). Patient satisfaction, stress and burnout in nursing personnel in emergency departments: A cross-sectional study. International Journal of Nursing Studies, 59, 60-67. https://doi.org/10.1016/j.ijnurstu.2016.02.008

Rudow, B. (1999). Stress and Burnout in the Teaching Profession: European Studies, Issues, and Research Perspectives. In R. V. A. M. Huberman (Ed.), Understanding and Preventing Teacher Burnout: A Sourcebook of International Research and Practice (pp. 38-58). New York, NY, US: Cambridge University Press. https://doi.org/10.1017/CBO9780511527784.004

Sandmark, H., Wiktorin, C., Hogstedt, C., Klenell-Hatschek, E.-K., \& Vingard, E. (1999). Physical work load in physical education teachers. Applied Ergonomics, 30(5), 435-442. https://doi.org/10.1016/S0003-6870(98)00048-9

Schaufeli, W. B., Leiter, M. P., \& Maslach, C. (2009). Burnout: 35 years of research and practice. Career Development International, 14(3), 204-220. https://doi.org/10.1108/136204 30910966406

Schwarzer, R., \& Hallum, S. (2008). Perceived teacher self-efficacy as a predictor of job stress and burnout: Mediation analyses. Applied Psychology, 57, 152-171. https://doi.org/ 10.1111/j.1464-0597.2008.00359.x

Shepherd, C. D., Tashchian, A., \& Ridnour, R. E. (2011). An investigation of the job burnout syndrome in personal selling. Journal of Personal Selling and Sales Management, 31, 397-409. https://doi.org/10.2753/PSS0885-3134310403

Skaalvik, E. M., \& Skaalvik, S. (2007). Dimensions of teacher self-efficacy and relations with strain factors, perceived collective teacher efficacy, and teacher burnout. Journal of Educational Psychology, 99, 611-625. https://doi.org/10.1037/0022-0663.99.3.611

Smith, D., \& Leng, G. W. (2003). Prevalence and sources of burnout in singapore secondary 


\section{Macrothink}

school physical education teachers. Journal of Teaching in Physical Education, 22(2), 203-218. https://doi.org/10.1123/jtpe.22.2.203

Toppinen-Tanner, S., Kalimo, R., \& Mutanen, P. (2002). The process of burnout in white-collar and blue-collar jobs: Eight-year prospective study of exhaustion. Journal of Organisational Behavior, 23, 555-570. https://doi.org/10.1002/job.155

Trudeau, F., Laurencelle, L., \& Lajoie, C. (2015). Energy expenditure at work in physical education teachers. Applied Ergonomics, 46(A), 218-223. https://doi.org/10.1016/j.apergo. 2014.08.010

Van Droogenbroeck, F., \& Spruyt, B. (2015). Do teachers have worse mental health? Review of the existing comparative research and results from the Belgian Health Interview Survey. Teaching and Teacher Education, 51, 88-100. https://doi.org/10.1016/j.tate.2015.06.006

Vancampfort, D., Correll, C. U., Scheewe, T. W., Probst, M., De Herdt, A., Knapen, J., \& De Hert, M. (2013). Progressive muscle relaxation in persons with schizophrenia: A systematic review of randomized controlled trials. Clinical Rehabilitation, 27(4), 291-298. https://doi.org/10.1177/0269215512455531

Yoon, B. (2008). Uninvited guests: The influence of teachers' roles and pedagogies on the positioning of English language learners in the regular classroom. American Educational Research Journal, 45, 495-522. https://doi.org/10.3102/0002831208316200

Zhang, Q., \& Sapp, D. A. (2008). A burning issue in teaching: The impact of teacher burnout and nonverbal immediacy on student motivation and affective learning. Journal of Communication Studies, 1(2), 152-168.

\section{Copyright Disclaimer}

Copyright for this article is retained by the author(s), with first publication rights granted to the journal.

This is an open-access article distributed under the terms and conditions of the Creative Commons Attribution license (http://creativecommons.org/licenses/by/3.0/). 